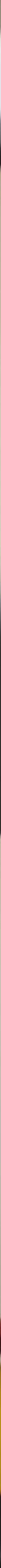




\section{Chronic disease in the elderly: back to the future of internal medicine}

\section{Educational aims}

1 To increase the interest of chest physicians in multiple chronic comorbidities in the elderly.

1 To define the most important and frequent comorbidities in elderly patients, particularly those with COPD.

1 To provide updated information on the most common chronic diseases present in the elderly.

1 To emphasise the limitations of single disease-oriented clinical practice guidelines, and the need for a more comprehensive "internistic" approach to patients with multiple chronic comorbidities.

1 To suggest that chronic inflammation might represent the common pathogenetic link between the different chronic diseases present in the elderly.

\section{Summary}

Elderly people are often affected by two or more chronic diseases, more frequently cardiovascular diseases, chronic respiratory diseases, metabolic syndrome and cancer. These most frequent chronic diseases share largely preventable risk factors, the most important being smoking and obesity, and may be linked to chronic systemic inflammation. Coexisting chronic diseases affect the course of the primary disease and alter the efficacy and safety of its management. Current clinical practice is dominated by the "singledisease" approach, which has major limitations, and there is increasing evidence that a patient-oriented approach that takes into account the several co-existing components of chronic disease is required. This "change of concept" implies the need for medical specialists to extend their expertise to broader diagnostic and treatment approaches that are traditionally the purview of internal medicine. This new approach also requires a different approach to clinical research and teaching, followed by extensive rewriting of medical textbooks and remodelling of teaching curricula to reflect the complexity of the patient affected by chronic diseases.

The most important and preventable chronic diseases (cardiovascular diseases, cancer, chronic respiratory diseases and diabetes) increase in frequency and severity with age [1-3]. Chronic diseases share largely preventable risk factors, the most important and preventable being smoking and obesity $[4,5]$. Individual chronic diseases, e.g. chronic heart failure (CHF) and chronic obstructive pulmonary disease (COPD), almost never develop alone but invariably develop together with one or more chronic comorbidities $[6,7]$. More than half of elderly people ( $\geq 65$ years) have at least three chronic medical conditions, and a significant proportion have five or more [8].

Obviously, such coexisting illnesses can
L.M. Fabbri ${ }^{1}$

R. Ferrari²

1Dept of Respiratory Diseases,
University of Modena and
Reggio Emilia, Modena, and
2Dept of Cardiology, University
of Ferrara, Ferrara, Italy.

Correspondence:

L.M. Fabbri

Clinica di Malattie dell'Apparato

Respiratorio

Università degli Studi di Modena e

Reggio Emilia

Policlinico Universitario di Modena Largo del Pozzo 71

I-41100 Modena

Italy

Fax: 390594224231

E-mail:fabbri.leonardo@unimo.it

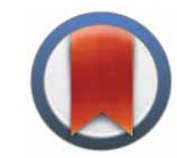

CrossMark \& click for updates 
affect the course of the primary disease, and alter the efficacy and safety of its management. Thus, while we continue to diagnose and assess the severity of single chronic diseases, we urgently need to re-assess the terminology and devise new criteria for the diagnosis and management of patients affected by more than one chronic disease.

Each component of a chronic disease, i.e. each comorbidity, can be classified into one of four categories: 1) causal (diseases with a common pathophysiology, such as coronary artery disease and myocardial infarction, emphysema and COPD); 2) complicating (disease-specific complicating morbidity, such as pneumonia in COPD or thromboembolism in CHF); 3) concurrent co-existing chronic morbidity without any known causal relationship with the index disease (such as gastritis and CHF or COPD); and 4) intercurrent (interacting acute illness, usually limited in time, such as colds or influenza in CHF or COPD) [9].

Chronic diseases make up a huge proportion of human illness [10]. Up to 35 million people were projected to die in 2005 from heart disease, stroke, cancer and other chronic diseases (figure 1). Excluding cancer, cardiovascular disease $(30 \%$ of projected total worldwide deaths in 2005), chronic respiratory diseases (7\%) and diabetes (2\%) are the most frequent chronic degenerative disorders [1-3]. An unprecedented increase in chronic degenerative disorders is expected in the next 10 years, and this is of great concern to the health authorities $[1,3]$; thus, chronic disease is a particularly important area in which to implement prevention strategies and to ensure high-quality care. The two most important risk factors underlying chronic diseases, which are key to any population-wide strategy of control, are tobacco use and obesity. Both can be prevented and controlled. If these risk factors were eliminated, at least $80 \%$ of premature heart disease and strokes would be prevented, $80 \%$ of type 2 diabetes would be prevented, and more than $40 \%$ of cancers would be prevented. Comprehensive and integrated strategies to reduce these risks would have a major effect on this range of diseases $[1-3,11]$.

Patients with chronic diseases are usually $>50$ years and have multiple comorbidities $[2,3$, $12,13]$. Because of exclusion criteria, clinical trials on chronic disease select younger people with milder disease and underestimate the frequency of comorbidities, which may affect $80-90 \%$ of the elderly population [8]. For example, clinical trials show that COPD occurs in 20\% of patients with $\mathrm{CHF}$, whereas population studies show a higher prevalence $[14,15]$. Likewise, clinical trials show that CHF may occur in $>20 \%$ of patients with COPD, whereas population studies show a higher prevalence [15]. Thus, comorbidities are quite frequent and important: not only may they contribute to the severity of the patient's clinical manifestations, but they may also complicate its treatment, and they are, therefore, important to recognise and treat effectively $[8,15,16]$.

Both CHF and COPD may also be associated with metabolic disorders, e.g. diabetes [17] and osteoporosis [18], and with other chronic conditions, e.g. anaemia $[19,20]$, renal failure [21], rheumatoid arthritis [22, 23], Helicobacter pylori infection [24] and erectile dysfunction [25]. Patients presenting with chronic inflammatory disease show a higher prevalence of various types of cancer [26], possibly linked to systemic inflammation [27].

\section{COPD}

COPD is a nonspecific term referring to a set of conditions that develop progressively as a result of various disease processes, namely emphysema and bronchiolitis, in response to inhalation of irritants, primarily cigarette smoke $[28,29]$.

Considering the systemic nature of the inflammatory response to irritants, particularly cigarette smoke [30], there is increasing evidence that lung abnormalities are not the only conditions responsible for respiratory symptoms such as dyspnoea. Other factors which play a role include the chronic comorbidities that develop along with COPD, particularly $\mathrm{CHF}$, coronary and peripheral vascular diseases, and metabolic syndrome [7, 31]. Comorbidities are highly likely to affect health outcomes in COPD, and COPD patients are more likely to die from cardiovascular complications or cancer than from respiratory failure [7]. 
Progressive respiratory failure accounts for approximately one-third of COPD-related deaths; therefore, factors other than progression of lung disease must play a substantial role in COPD mortality. The most common comorbidities that have been described in association with COPD are hypertension, diabetes, coronary artery disease [32, 33], heart failure [15], pulmonary infections, cancer [26] and pulmonary vascular disease [7] (figure 2). The number of preexisting comorbidities in patients with COPD is associated with increased in-hospital mortality [33]. Comorbid conditions that have been associated with an increased mortality risk in COPD patients include chronic renal failure, pulmonary hypertension, right heart failure [34] and pulmonary vascular disease [35]. Underlying heart diseases have not been consistently associated with a higher mortality risk. However, since COPD is frequently under-reported, it is difficult to accurately estimate how comorbid conditions influence COPD mortality or, conversely, how COPD affects the outcome of other diagnoses [7].

There is a growing body of evidence that indicates that persistent low-grade systemic inflammation is present in stable COPD. Lowgrade systemic inflammation has been implicated in the pathogenesis of cardiovascular events and chronic myopathy of skeletal muscle. Since COPD patients suffer from excess morbidity and mortality related to cardiovascular events, it has been suggested that systemic inflammation may be the common link [36].

In conclusion, COPD is one of the leading causes of mortality and morbidity in the world, yet little is known about the prevalence and importance of comorbid conditions and specific causes of death in patients with COPD. Considering that patients with COPD die not of COPD but primarily of comorbid conditions, particularly cardiovascular diseases and lung cancer, and that the pharmacological treatment of COPD is only symptomatic, a more comprehensive approach to comorbidities and particularly to those that are preventable and treatable, such as cardiovascular and metabolic, may represent the only opportunity for the next several years to modify the natural history of COPD.

\section{CHF}

CHF is the leading cause of hospitalisation in older adults, and it is also an important cause of death and chronic disability [37]. Heart failure in the elderly differs in many respects from heart

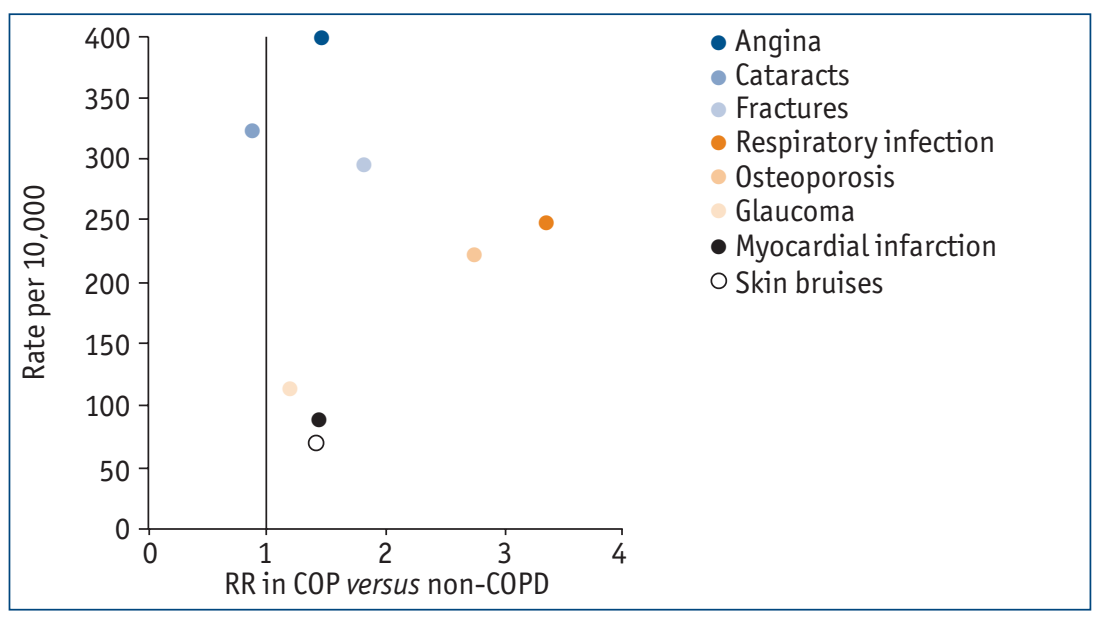

failure occurring during middle age. In particular, the diagnosis and treatment of heart failure in the elderly are often complicated by the presence of multiple cardiac and noncardiac comorbid conditions, many of which have important implications for the care of the older heartfailure patient [38].

$\mathrm{CHF}$ is the only common cardiovascular condition whose prevalence is increasing, especially in the elderly $[6,37]$. It is often the expression of end-stage cardiac disease, when half of the patients diagnosed with CHF will be dead within 5 years. Increasing prevalence, hospitalisations and deaths have made CHF a major chronic condition in Western countries and a major cause of death worldwide.

Comorbidities are common in CHF, particularly in the elderly [38]. The most common ones are chronic coronary and peripheral artery diseases $(>50 \%)$, arterial hypertension ( $50 \%)$, diabetes (20-30\%), COPD (20-30\%) and anaemia (20-30\%), all of which affect severity, morbidity, hospitalisation and mortality $[12,39]$ (table 1).

\section{Systemic arterial hypertension}

The diagnosis of arterial hypertension depends on repeated occurrences of higherthan-normal systolic and/or diastolic blood pressure [40]. An untreated hypertensive patient is at great risk of experiencing disabling or fatal left ventricular failure, myocardial infarction, cerebral haemorrhage or infarction, or renal failure at an early age [40]. Arterial hypertension is the most important risk factor predisposing to stroke [40]. It is one of three risk factors (along with cigarette smoking and hypercholesterolaemia) predisposing to
Figure 2

Relationship between rate per 10,000 of selected medical events and their relative risk (RR) in COPD versus non-COPD patients $>65$ years old. Figure reprinted with permission from [32]. 


\section{Table 1 Epidemiological data on the prevalence of hypertension (HT), diabetes (DM), COPD and anaemia in patients with heart failure (HF)}

\begin{tabular}{|c|c|}
\hline Study & Results \\
\hline \multicolumn{2}{|l|}{ Hypertension } \\
\hline BRAUNSTEIN et al. [6] & $\begin{array}{l}55 \% \text { had HT and } 11 \% \text { severe HT in the Medicare study } \\
\text { (n=122,630 patients) }\end{array}$ \\
\hline Ho et al. [7] & $39 \%$ of males and $59 \%$ of females had HT in the \\
\hline Lewet al. [8] & Framingham study \\
\hline GUSTAFSSON et al. [9] & $\begin{array}{l}27 \% \text { of the males and } 22 \% \text { of the females had HT in the } \\
\text { Danish Diamond study ( } n=5,491 \text { patients) }\end{array}$ \\
\hline HIMMELMAN [10] & At least $50 \%$ of patients with HT developed HF \\
\hline \multicolumn{2}{|l|}{ Diabetes } \\
\hline KANNEL et al. [24] & $\begin{array}{l}\text { Risk for developing HF in young males and females with } \\
\text { DM (2.20 and 5.37, respectively) }\end{array}$ \\
\hline SHINDLER et al. [25] & $\begin{array}{l}\text { In the SOLVD study } 15 \% \text { in the prevention trial and } 26 \% \\
\text { in the treatment trial had DM }\end{array}$ \\
\hline CoHn et al. [26] & Similar results in the V-HeFT II trial (26\%) had DM \\
\hline Consensus trial [27] & $23 \%$ developed DM in the CONSENSUS trial \\
\hline RYDEN et al. [28] & 19\% developed DM in the ATLAS study \\
\hline SHINDLER et al. [25] & In the SOLVD registry ( $n=6,076$ patients) $23 \%$ had DM \\
\hline ZANNAD et al. [29] & In the French registry study EPICAL $26 \%$ had DM \\
\hline BRAUNSTEIN et al. [6] & In the Medicare study ( $n=122,630$ patients) $31 \%$ had DM \\
\hline StRATIION et al. [30] & $\begin{array}{l}\text { Interrelationship between } \mathrm{HbA1c} \text { levels and incidence of } \\
\mathrm{HF}\end{array}$ \\
\hline IRIBARREN et al. [31] & $\begin{array}{l}\text { Each } 1 \% \text { increase in } \mathrm{HbA1c} \text { was associated with } 8 \% \\
\text { increased risk of developing HF }\end{array}$ \\
\hline PaOLISSO et al. [32] & $\begin{array}{l}\text { Whole body insulin resistance is prevalent in HF patients } \\
\text { with either ischaemic or idiopathic dilated cardiomyopathy }\end{array}$ \\
\hline Swam et al. [33] & Similar results as in PAOLISSO et al. [32] \\
\hline \multicolumn{2}{|l|}{ COPD } \\
\hline BRAUNSTEIN et al. [6] & In the Medicare study $26 \%$ of patients had COPD \\
\hline GUSTAFSSON et al. [9] & In the Danish Diamond study 22\% had COPD \\
\hline Ni et al. [53] & In this study only $10 \%$ had COPD \\
\hline McCuLlough et al. [54] & $\begin{array}{l}\text { In this emergency department study } 21 \% \text { of the } \\
\text { patients had COPD }\end{array}$ \\
\hline \multicolumn{2}{|l|}{ Anaemia } \\
\hline TANNER et al. [59] & The prevalence of anaemia was $15 \%$ \\
\hline EZEKowII et al. [60] & The prevalence of anaemia was $17 \%$ \\
\hline SILVERBERG et al. [61] & $\begin{array}{l}\text { The prevalence of anaemia was 50\% and in patients } \\
\text { with severe HF } 80 \%\end{array}$ \\
\hline KOMAJDA [62] & $\begin{array}{l}\text { In this review the prevalence of anaemia and its clinical } \\
\text { characteristics are discussed }\end{array}$ \\
\hline
\end{tabular}

coronary atherosclerosis. The higher the blood pressure and the more severe the changes in the retina, the worse the prognosis. Fewer than $5 \%$ of patients with group 4 or malignant hypertension characterised by papilloedema and $<10 \%$ of patients with group 3 changes in the fundus survive 1 year without treatment. Effective medical control of hypertension will prevent or forestall most complications and will prolong life in patients with isolated systolic or diastolic hypertension [40].

Coronary artery disease is the most common cause of death among treated hypertensive patients. Systolic blood pressure is a more important predictor of fatal and nonfatal cardiovascular events than diastolic blood pressure. In a follow-up of males screened for the Multiple Risk Factor Intervention Trial, overall mortality was related to systolic blood pressure, regardless of diastolic blood pressure. Arterial hypertension is a frequent comorbidity of most chronic diseases $[41]$, e.g. up to $40 \%$ in COPD $[25,42]$, CHF [12, 39,43 ] and in renal failure [44], and it is an important component of the cardiometabolic syndrome $[4,45]$.

\section{Atherosclerosis, coronary and peripheral vascular diseases}

Vascular diseases include coronary artery disease and peripheral arterial disease, a term that encompasses a range of non-coronary arterial syndromes that are caused by the altered structure and function of the arteries that supply the brain, the visceral organs and the limbs. Vascular diseases are caused primarily by atherosclerosis and thromboembolic pathophysiological processes that alter the normal structure and function of the aorta, its visceral arterial branches and the arteries of the lower extremities $[46,47]$.

As atherosclerosis is the most common cause of coronary and peripheral artery disease worldwide, the epidemiology and clinical consequences of peripheral arterial disease are closely associated with classic atherosclerosis risk factors (smoking, diabetes, hypertension, hyperlipidaemia, family history and post-menopausal state) and more recently defined risk factors (e.g. hyperhomocysteinaemia) $[46,47]$.

Coronary vascular diseases and peripheral arterial disease are often associated, and the prognosis of patients with peripheral arterial disease is characterised by an increased risk for cardiovascular ischaemic events due to concomitant coronary artery disease and cerebrovascular disease. The relative prevalence of coronary and cerebral atherosclerosis depends on the criteria used to establish the diagnosis. In approximately one-third to one-half of patients presenting with peripheral arterial disease, evidence of coronary artery disease is based on clinical history and electrocardiogram; in two-thirds of patients, it is based on an abnormal stress test.

The majority of individuals with lowerextremity peripheral artery disease do not experience recognisable limb ischaemic symptoms; by this 
definition they are "asymptomatic", which implies the absence of classic intermittent claudication. Individuals with asymptomatic lowerextremity peripheral artery disease do not enjoy a benign prognosis, because most have systemic atherosclerotic disease. These individuals are characterised by a risk factor profile comparable to that of individuals with symptomatic lowerextremity peripheral artery disease [47]. Patients with vascular disorders can usually be assured that an accurate anatomical diagnosis will be made with modern non-invasive vascular diagnostic techniques (e.g. ankle- and toe-brachial indices, segmental pressure measurements, pulse volume recordings, duplex ultrasound imaging, Doppler waveform analysis and exercise testing). These tests will usually provide adequate information for creation of a therapeutic plan [47].

As a consequence of co-existing coronary and cerebrovascular disease, there is an increased risk of myocardial infarction, stroke and cardiovascular death in patients with lowerextremity peripheral arterial disease [47]. Systemic complications and comorbidities of atherosclerosis, and chronic coronary and peripheral vascular diseases include myocardial infarction [47, 48], stroke [49], renal failure [48, 50], erectile dysfunction [51], rheumatoid arthritis [22], diabetes and dementia [52].

\section{Metabolic syndrome}

Metabolic syndrome is a complex disorder and an emerging clinical challenge, recognised by the findings of abdominal obesity, elevated triglycerides, atherogenic dyslipidaemia, elevated blood pressure, high blood glucose and/or insulin resistance [53]. Metabolic syndrome is also characterised by a prothrombotic state and a proinflammatory state. Central pathophysiological features of metabolic syndrome include: 1) insulin resistance; 2) atherogenic dyslipidaemia; 3) arterial hypertension, which occurs frequently in persons with insulin resistance; 4) a proinflammatory state, with increases in acutephase reactants (e.g. C-reactive protein); and 5) a prothrombotic state, with increases in plasminogen activator inhibitor-1 and fibrinogen [53]. The risk of mortality and of major cardiovascular events increases two- to fourfold in individuals affected by metabolic syndrome or type 2 diabetes, relative to those without metabolic disease [54], and metabolic modulation is altered in COPD [55].
Inflammation is an important risk factor in cardiovascular disease and diabetes mellitus, and adding inflammatory markers to the definition of metabolic syndrome improves the prediction of cardiovascular diseases and diabetes. Elevated hs-C-reactive protein levels may also be predictive of development of metabolic syndrome, suggesting that systemic inflammation plays the key pathogenetic role in metabolic syndrome and its comorbidities [56]. Diabetes has been estimated to account for 1.1 million deaths in 2005, but it is related to many more fatalities, because, although people might live for years with diabetes, their deaths are usually recorded as being caused by heart disease, kidney failure or chronic respiratory diseases [11].

\section{Osteoporosis}

Osteoporosis is a common and preventable disorder of the older adult skeleton that predisposes an individual to an increased risk of fracture, a major cause of disability in older adults [57]. Most patients with osteoporosis have an identifiable cause of bone loss. Osteoporosis is often associated with chronic cardiovascular and respiratory diseases [58] and COPD [18], and, like most chronic conditions, benefits from physical activity [59], particularly in the elderly.

\section{Muscle wasting}

Cachexia (derived from the Greek kakos (bad) and hexis (condition)) is characterised by accelerated loss of skeletal muscle and poor responsiveness to nutritional interventions $[60,61]$. Cachectic patients exhibit changes in the metabolism of proteins, lipids and carbohydrates that are thought to be related to systemic inflammation; although systemic inflammation is considered an effect of individual chronic conditions, e.g. COPD, CHF, renal failure and cancer, it is, in fact, very similar in both pathogenetic mechanisms and clinical manifestations in the various chronic diseases [60].

\section{Anaemia}

Anaemia is frequently associated with chronic illnesses such as $\mathrm{CHF}$, with inflammatory diseases such as rheumatoid arthritis, with chronic infectious disorders, and with cancer [20]. Anaemia in chronic illness is characterised by weakness, fatigue, cachexia and poor nutritional state, and 


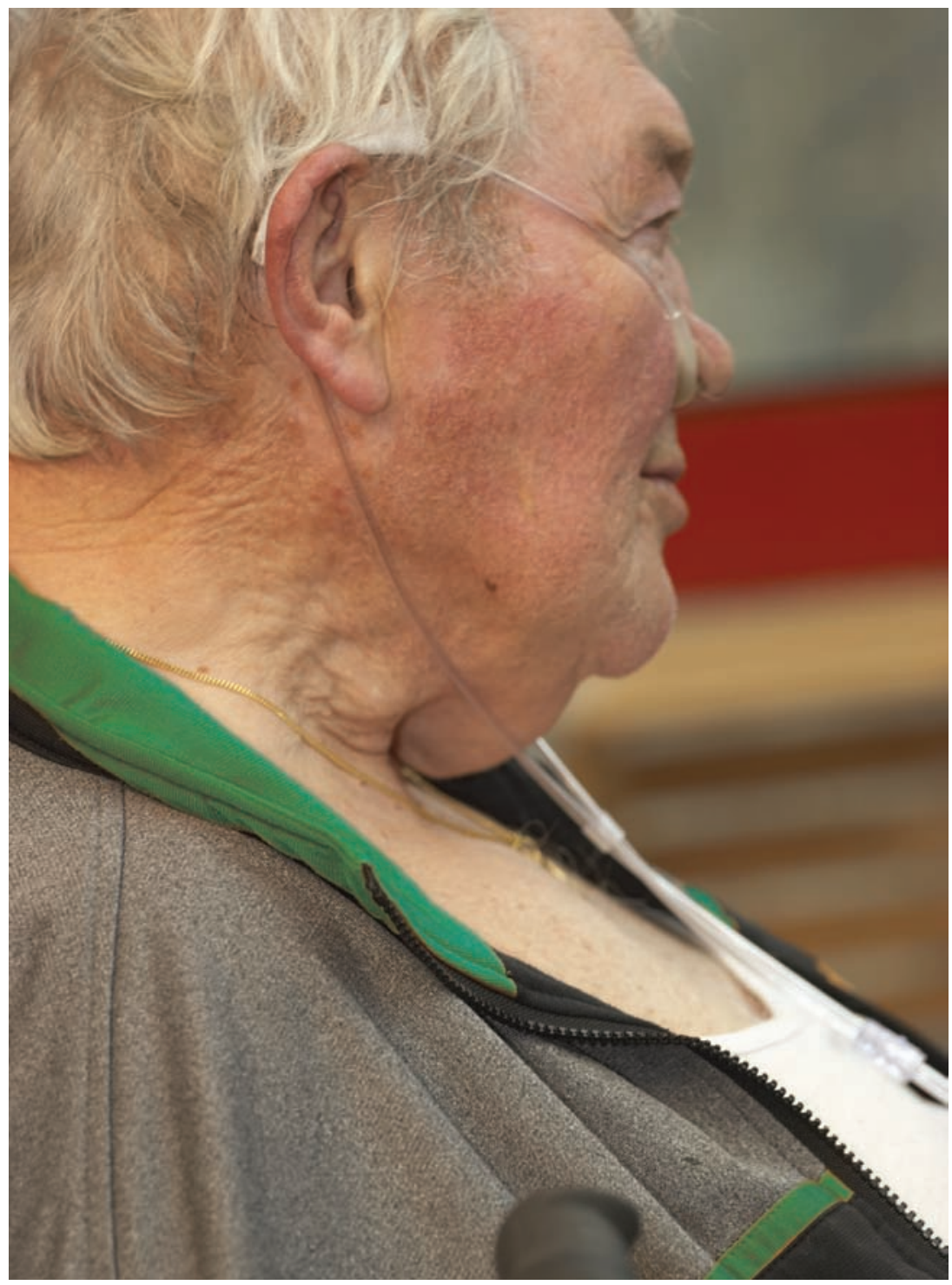

by impaired mood, cognitive functions and quality of life [62]. It has been suggested that anaemia to some extent contributes to exercise limitation and dyspnoea in chronic illness [63].

Anaemia also frequently occurs in patients with COPD [20]. Inadequate haemoglobin levels could aggravate tissue hypoxia and carry a negative prognostic impact. Blood cell transfusion in anaemic COPD patients reduces minute ventilation and the work of breathing [64], suggesting that correcting low haemoglobin levels could alleviate dyspnoea and improve exercise capacity. In a small set of anaemic ventilator-dependent COPD patients, raising haemoglobin levels to $>12 \mathrm{~g} \cdot \mathrm{dL}^{-1}$ seemed to improve patients enough to make ventilator weaning possible. A reduced haematocrit was found to be an independent predictor of poor outcomes in COPD patients following elective open abdominal aortic aneurysm resection [65].

\section{CRF}

Chronic renal failure (CRF) is a gradual and progressive loss of the ability of the kidneys to excrete waste, concentrate urine and conserve electrolytes. It most often results from any disease that causes gradual loss of kidney function. It can range from mild dysfunction to severe kidney failure, and progression may continue to end-stage renal disease, which is associated with important comorbidities [66]. CRF and endstage renal disease affect more than two out of 1,000 people in the USA. Diabetes and hypertension (high blood pressure) account for approximately two-thirds of the cases of CRF and end-stage renal disease. Most body systems are affected by CRF, and fluid retention and uraemia can cause many complications. A recent study showed that both renal failure and ischaemic heart disease were highly relevant to the prognosis of COPD patients discharged from hospital after an acute exacerbation. These comorbid diseases probably acted as markers of frailty by increasing the fatality rate of further COPD exacerbations [67].

\section{Single disease versus patient-oriented guidelines}

Clinical practice guidelines are increasingly being used as performance indicators, and have been shown to substantially improve the quality of clinical care. However, most clinical practice guidelines ignore the fact that the majority of individuals with a chronic disease have one or more chronic comorbidities, e.g. COPD, CHF, peripheral artery disease, diabetes or non-lifethreatening cancer, that may have a major impact, particularly in the elderly [68]. Thus, although comorbidities are quite frequent in clinical practice, most evidence-based, disease-oriented diagnostic and treatment strategies overlook them $[8,9]$. It is, therefore, evident that clinical practice guidelines, designed largely by specialty-dominated committees for managing single diseases, provide clinicians with little guidance in caring for older patients with multiple chronic diseases.

Treatment or even diagnosis of a disease might interact negatively or positively with the treatment or natural course of a co-existing disease $[8,69]$. For example, treatment of exacerbations of COPD includes oral corticosteroids, 
which may not be recommended if the patient also has diabetes mellitus; $\beta$-blockers are recommended for CHF but might have adverse effects in patients who also have asthma or COPD. Conversely, statins, which are used primarily as lipid-lowering agents in the treatment of metabolic syndrome, have potent anti-inflammatory properties that might positively affect comorbidities of metabolic syndrome, e.g. COPD, $\mathrm{CHF}$ and vascular diseases [70-73]. However, the most recent guidelines for COPD and CHF refer only marginally to comorbidities and do not include them in the assessment of severity and do not refer one to the other $[28,37]$.

\section{Chronic inflammation as the common link}

The systemic effects of exposure to cigarette smoke and atmospheric particles were recently nicely reviewed $[5,7]$. Cigarette smoke and atmospheric particles stimulate the bone marrow to release leukocytes, such as neutrophils and monocytes, as well as platelets. The bone marrow's response is related to the intensity of exposure of alveolar macrophages to particles and to their release of mediators as a response to these particles [74-77]. Circulating cytokines and chemokines (e.g. interleukin (IL)-6 and IL-1) and granulocyte-macrophage colony-stimulating factor increase after exposure to ambient particles, and they stimulate the bone marrow [74]. Tumour necrosis factor $\alpha$ and IL-1 are "acute response" cytokines that, together with IL-6, are responsible for initiation of the acute-phase response [78]. Together, these cytokines have the ability to elicit a systemic inflammatory response characterised by an increase in circulating leukocytes, platelets, and proinflammatory and prothrombotic proteins [78]. This response generates C-reactive protein, fibrinogen and other coagulation factors, all of which have been associated with thromboembolic cardiovascular events. This response also has the ability to activate circulating leukocytes and the endothelium of the vascular bed to promote leukocyte-ndothelial adhesion and migration [78]. Cigarette smoke and pollutants, like infectious organisms, activate alveolar macrophages, bronchial epithelial cells and other cellular elements in the airways, particularly in genetically susceptible individuals [79]. Once activated, these cells produce a variety of signalling molecules, chemokines and cytokines, e.g. IL-8, which recruits neutrophils; macrophage chemotactic protein-1, which recruits monocytes; and interferon-y-inducible protein-10, which recruits lymphocytes [78]. Additionally, these cells stimulate the synthesis and release of growth factors, elastolytic enzymes and metalloproteinases, which, by themselves, may promote emphysematous changes in lung parenchyma and airway remodelling [80, 81]. Systemic inflammation is also present in COPD and, on a cross-sectional basis, has been linked with cardiac ischaemic events, suggesting that systemic inflammation may contribute to the causal pathway, linking COPD, in particular, with cardiovascular complications [7].

Thus, there is a growing body of evidence to indicate that persistent low-grade systemic inflammation is present in all components of the chronic diseases, and that chronic systemic inflammation may be the link between them (figure 3) (reviewed in references [7] and [36]). For example, if systemic inflammation is a key mechanism for atherosclerosis, patients suffering from conditions associated with systemic inflammation should have an excess risk of cardiovascular morbidity and mortality. Atherosclerosis is a progressive disease characterised by accumulation of lipids, fibrous tissue and inflammatory cells in arteries. Although the pathogenesis of atherosclerosis is complex and multifactorial, persistent, low-grade systemic inflammation is believed to be one of the central events leading to plaque formation. There are strong epidemiological data linking systemic inflammation to

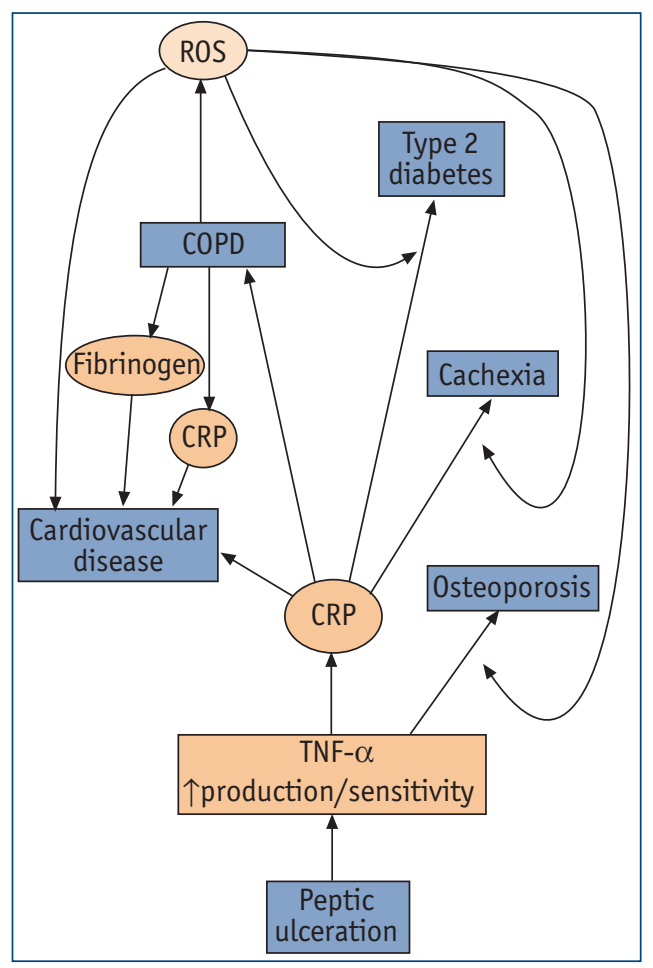

\section{Educational questions}

1. What are the main causes of death in patients with COPD?

a) Cardiovascular diseases.

b) Lung cancer.

c) Respiratory failure.

d) Renal failure.

2. The prevalence of COPD in patients with chronic heart failure is close to:
a) $70 \%$
b) $50 \%$
c) $20 \%$
d) $10 \%$

3. The relative risk of diabetes in subjects with COPD is close to:
a) 1
b) 4
c) 2
d) 3

4. The deaths attributable to smoking are mainly:
a) COPD.
b) Diabetes.
c) Cancer.
d) Cardiovascular diseases

\section{Figure 3}

The central role of inflammation, particularly reactive oxygen species (ROS), C-reactive protein (CRP) and tumour necrosis factor (TNF)- $\alpha$, in comorbidities associated with COPD. Figure reprinted with permission from [36]. 


Suggested answers
1. a
2. c
3. c
4. d

atherosclerosis, ischaemic heart disease, strokes and coronary deaths [82]. Under normal physiological conditions (and without external insults), the human endothelium does not support leukocyte adhesion, which is the building block of plaque genesis. However, in an inflammatory state (such as diabetes, COPD or obesity), the endothelium begins to overexpress surface adhesion molecules, such as vascular cell adhesion molecule-1, that allow circulating white blood cells to adhere to damaged endothelial surfaces. Once the white cells adhere to the endothelium, they trigger a whole series of inflammatory reactions.

\section{Conclusion}

In conclusion, two or more chronic diseases almost invariably develop together in the same patient, particularly in the elderly, often making it difficult to establish a proper diagnosis and assessment of severity. The current clinical practice is dominated by the "single-disease" approach, which has major limitations, whereas there is increasing evidence that a patientoriented approach that takes into account the several co-existing components of chronic disease is required. This "change of concept" implies the need for medical specialists to extend their expertise to broader diagnostic and treatment approaches that are traditionally the purview of internal medicine. This new approach also requires a different approach to clinical research and teaching, followed by extensive rewriting of medical textbooks and remodelling of teaching curricula to reflect the complexity of the patient affected by chronic disease.

\section{Acknowledgements}

The authors would like to thank M. McKenney for editing the manuscript and E. Veratelli for her scientific secretarial assistance.

\section{References}

1. Horton R. The neglected epidemic of chronic disease. Lancet 2005; 366: 1514.

2. Strong K, Mathers C, Leeder S, Beaglehole R. Preventing chronic diseases: how many lives can we save? Lancet 2005; 366: 1578-1582.

3. Epping-Jordan JE, Galea G, Tukuitonga C, Beaglehole R. Preventing chronic diseases: taking stepwise action. Lancet $2005 ; 366: 1667-1611$.

4. Poirier P, Giles TD, Bray GA, et al. Obesity and cardiovascular disease: pathophysiology, evaluation, and effect of weight loss. Arterioscler Thromb Vasc Biol 2006; 26: 968-976.

5. Rempher KJ. Cardiovascular sequelae of tobacco smoking. Crit Care Nurs Clin North Am 2006; 18: 13-20, xi.

6. De Backer G, Ambrosioni E, Borch-Johnsen K, et al. European guidelines on cardiovascular disease and prevention in clinical practice. Atherosclerosis $2003 ; 171$ : $145-155$.

7. Mannino DM, Watt G, Hole D, et al. The natural history of chronic obstructive pulmonary disease. Eur Respir J 2006; $27: 627-643$.

8. Boyd CM, Darer J, Boult C, Fried LP, Boult L, Wu AW. Clinical practice guidelines and quality of care for older patients with multiple comorbid diseases: implications for pay for performance. JAMA 2005; 294: 716-724.

9. van Weel C, Schellevis FG. Comorbidity and guidelines: conflicting interests. Lancet 2006; 367: 550-551.

10. Lopez AD, Mathers CD, Ezzati M, Jamison DT, Murray CJ. Global and regional burden of disease and risk factors, 2001: systematic analysis of population health data. Lancet 2006; 367: 1747-1757.

11. Beaglehole R, Epping-Jordan J, Strong K, Mathers C. The Lancet's chronic diseases series - Authors' reply. Lancet 2006; $367: 564-565$.

12. Braunstein JB, Anderson GF, Gerstenblith G, et al. Noncardiac comorbidity increases preventable hospitalizations and mortality among Medicare beneficiaries with chronic heart failure. J Am Coll Cardiol 2003; 42: 1226-1233.

13. Rutten FH, Moons KG, Cramer MJ, et al. Recognising heart failure in elderly patients with stable chronic obstructive pulmonary disease in primary care: cross sectional diagnostic study. BMJ 2005; 331: 1379.

14. Havranek EP, Masoudi FA, Westfall KA, Wolfe P, Ordin DL, Krumholz HM. Spectrum of heart failure in older patients: results from the National Heart Failure project. Am Heart J 2002; 143: 412-417.

15. Sin DD, Man SF. Chronic obstructive pulmonary disease as a risk factor for cardiovascular morbidity and mortality. Proc Am Thorac Soc 2005; 2: 8-11.

16. Rutten FH, Cramer MJ, Lammers JW, Grobbee DE, Hoes AW. Heart failure and chronic obstructive pulmonary disease: an ignored combination? Eur J Heart Fail 2006; (In press).

17. Rana JS, Mittleman MA, Sheikh J, et al. Chronic obstructive pulmonary disease, asthma, and risk of type 2 diabetes in women. Diabetes Care 2004; 27: 2478-2484.

18. Jorgensen NR, Schwarz P, Holme I, Henriksen BM, Petersen LJ, Backer V. The prevalence of osteoporosis in patients with chronic obstructive pulmonary disease-A cross sectional study. Respir Med 2006; (In press).

19. Chambellan A, Chailleux E, Similowski T. Prognostic value of the hematocrit in patients with severe COPD receiving long-term oxygen therapy. Chest 2005; 128: $1201-1208$.

20. Similowski T, Agusti A, MacNee W, Schonhofer B. The potential impact of anaemia of chronic disease in COPD. Eur Respir J 2006; 27: 390-396.

21. Witczak B, Hartmann A, Svennevig JL. Multiple risk assessment of cardiovascular surgery in chronic renal failure patients. Ann Thorac Surg $2005 ; 79: 1297-1302$.

22. Gerli R, Goodson NJ. Cardiovascular involvement in rheumatoid arthritis. Lupus 2005; 14: 679-682.

23. Thomas E, Symmons DP, Brewster DH, Black RJ, Macfarlane GJ. National study of cause-specific mortality in rheumatoid arthritis, juvenile chronic arthritis, and other rheumatic conditions: a 20 year followup study. J Rheumatol 2003; 30: 958-965.

24. Roussos A, Philippou N, Krietsepi V, et al. Helicobacter pylori seroprevalence in patients with chronic obstructive pulmonary disease. Respir Med 2005; 99: 279-284.

25. Koseoglu N, Koseoglu H, Ceylan E, Cimrin HA, Ozalevli S, Esen A. Erectile dysfunction prevalence and sexual function status in patients with chronic obstructive pulmonary disease. J Urol 2005; 174: 249-252; discussion 252.

26. Thun MJ, Henley SJ, Gansler T. Inflammation and cancer: an epidemiological perspective. Novartis Found Symp 2004; 256: 6-21; discussion 22-28, 49-52, 266-269.

27. Balkwill F, Mantovani A. Inflammation and cancer: back to Virchow? Lancet 2001; 357: 539-545.

28. Global Initiative for Chronic Obstructive Lung Disease. Update 1 July 2005. A collaborative project of the National Heart, Lung and Blood Institute, NIH and the World Health Organization. www.goldcopd.com.

29. Celli BR, MacNee W. Standards for the diagnosis and treatment of patients with COPD: a summary of the ATS/ERS position paper. Eur Respir J 2004; $23: 932-946$.

30. Ambrose JA, Barua RS. The pathophysiology of cigarette smoking and cardiovascular disease: an update. J Am Coll Cardiol 2004; 43: $1731-1737$.

31. Agusti AG. Systemic effects of chronic obstructive pulmonary disease. Proc Am Thorac Soc 2005; 2: 367-370; discussion 371-372.

32. Soriano JB, Visick GT, Muellerova H, Payvandi N, Hansell AL. Patterns of comorbidities in newly diagnosed COPD and asthma in primary care. Chest 2005; $128: 2099-2107$. 
33. Sidney S, Sorel M, Quesenberry CP Jr, DeLuise C, Lanes S, Eisner MD. COPD and incident cardiovascular disease hospitalizations and mortality: Kaiser Permanente Medical Care Program. Chest 2005; 128: 2068-2075.

34. Naeije R. Pulmonary hypertension and right heart failure in chronic obstructive pulmonary disease. Proc Am Thorac Soc 2005; 2: 20-22.

35. Naeije R, Vizza D. Current perspectives modern hemodynamic evaluation of the pulmonary circulation. Application to pulmonary arterial hypertension and embolic pulmonary hypertension. Ital Heart J 2005; 6: 784-788.

36. Sevenoaks M, Stockley R. Chronic obstructive pulmonary disease, inflammation and co-morbidity - a common inflammatory phenotype? Respir Res $2006 ; 7: 70$.

37. Hunt SA. ACC/AHA 2005 guideline update for the diagnosis and management of chronic heart failure in the adult: a report of the American College of Cardiology/American Heart Association Task Force on Practice Guidelines (Writing Committee to Update the 2001 Guidelines for the Evaluation and Management of Heart Failure). $\mathrm{J}$ Am Coll Cardiol 2005; 46: e1-e82.

38. Rich MW. Heart failure in the oldest patients: the impact of comorbid conditions. Am J Geriatr Cardiol 2005; 14: 134-141.

39. Dahlstrom U. Frequent non-cardiac comorbidities in patients with chronic heart failure. Eur J Heart Fail 2005; 7: 309-316.

40. Whitworth JA, Chalmers J. World health organisation-international society of hypertension (WHO/ISH) hypertension guidelines. Clin Exp Hypertens 2004; $26: 747-752$.

41. Lackland DT. Systemic hypertension: an endemic, epidemic, and a pandemic. Semin Nephrol 2005; 25: 194-197.

42. Dhungel S, Paudel B, Shah S. Study of prevalence of hypertension in chronic obstructive pulmonary disease patients admitted at Nepal Medical College and Teaching Hospital. Nepal Med Coll J 2005; 7: 90-92.

43. Gradman AH, Alfayoumi F. From left ventricular hypertrophy to congestive heart failure: management of hypertensive heart disease. Prog Cardiovasc Dis 2006; 48: 326-341.

44. Kimmel PL. Update in nephrology and hypertension. Ann Intern Med 2006; 144: 281-285.

45. Govindarajan G, Whaley-Connell A, Mugo M, Stump C, Sowers JR. The cardiometabolic syndrome as a cardiovascular risk factor. Am J Med Sci $2005 ; 330: 311-318$.

46. Hankey GJ, Norman PE, Eikelboom JW. Medical treatment of peripheral arterial disease. JAMA 2006; 295: 547-553.

47. Hirsch AT, Haskal ZJ, Hertzer NR, et al. ACC/AHA 2005 Practice Guidelines for the management of patients with peripheral arterial disease (lower extremity, renal, mesenteric, and abdominal aortic): a collaborative report from the American Association for Vascular Surgery/Society for Vascular Surgery, Society for Cardiovascular Angiography and Interventions, Society for Vascular Medicine and Biology, Society of Interventional Radiology, and the ACC/AHA Task Force on Practice Guidelines (Writing Committee to Develop Guidelines for the Management of Patients With Peripheral Arterial Disease): endorsed by the American Association of Cardiovascular and Pulmonary Rehabilitation; National Heart, Lung, and Blood Institute; Society for Vascular Nursing; TransAtlantic Inter-Society Consensus; and Vascular Disease Foundation. Circulation 2006; 113: e463-e654.

48. Campean V, Neureiter D, Varga I, et al. Atherosclerosis and vascular calcification in chronic renal failure. Kidney Blood Press Res 2005; 28: $280-289$.

49. Sanossian N, Ovbiagele B. Multimodality stroke prevention. Neurologist 2006; 12: 14-31.

50. Blacher J, Safar ME. Large-artery stiffness, hypertension and cardiovascular risk in older patients. Nat Clin Pract Cardiovasc Med 2005; 2: 450-455.

51. Billups KL, Bank AJ, Padma-Nathan H, Katz S, Williams R. Erectile dysfunction is a marker for cardiovascular disease: results of the minority health institute expert advisory panel. J Sex Med 2005; 2: 40-50; discussion 50-52.

52. Messier C, Awad N, Gagnon M. The relationships between atherosclerosis, heart disease, type 2 diabetes and dementia. Neurol Res 2004; 26: 567-572.

53. Grundy SM, Cleeman JI, Daniels SR, et al. Diagnosis and management of the metabolic syndrome: an American Heart Association/National Heart, Lung, and Blood Institute Scientific Statement. Circulation 2005; 112: 2735-2752.

54. Lakka HM, Laaksonen DE, Lakka TA, et al. The metabolic syndrome and total and cardiovascular disease mortality in middle-aged men. JAMA 2002; 288: 2709-2716.

55. Schols AM. Nutritional and metabolic modulation in chronic obstructive pulmonary disease management. Eur Respir J 2003; 22: Suppl. 46, 81s-86s.

56. Haffner SM. The metabolic syndrome: inflammation, diabetes mellitus, and cardiovascular disease. Am J Cardiol 2006; 9: 3A-11A.

57. Wilkins CH, Birge SJ. Prevention of osteoporotic fractures in the elderly. Am J Med 2005; 118: 1190-1195.

58. McFarlane SI, Muniyappa R, Shin JJ, Bahtiyar G, Sowers JR. Osteoporosis and cardiovascular disease: brittle bones and boned arteries, is there a link? Endocrine 2004; 23: 1-10.

59. Warburton DE, Nicol CW, Bredin SS. Health benefits of physical activity: the evidence. CMAJ 2006; 174: 801-809.

60. Morley JE, Thomas DR, Wilson MM. Cachexia: pathophysiology and clinical relevance. Am J Clin Nutr 2006; 83: 735-743.

61. Delano MJ, Moldawer LL. The origins of cachexia in acute and chronic inflammatory diseases. Nutr Clin Pract 2006; 21: 68-81.

62. Silverberg DS, Iaina A, Wexler D, Blum M. The pathological consequences of anaemia. Clin Lab Haematol 2001; 23: 1-6.

63. Kalra PR, Bolger AP, Francis DP, et al. Effect of anemia on exercise tolerance in chronic heart failure in men. Am J Cardiol 2003; 91: 888-891.

64. Schonhofer B, Wenzel M, Geibel M, Kohler D. Blood transfusion and lung function in chronically anemic patients with severe chronic obstructive pulmonary disease. Crit Care Med 1998; 26: 1824-1828.

65. Upchurch GR Jr, Proctor MC, Henke PK, et al. Predictors of severe morbidity and death after elective abdominal aortic aneurysmectomy in patients with chronic obstructive pulmonary disease. J Vasc Surg 2003; 37: 594-599.

66. Jassal SV, Schaubel DE, Fenton SS. Baseline comorbidity in kidney transplant recipients: a comparison of comorbidity indices. Am J Kidney Dis $2005 ; 46: 136-142$.

67. Antonelli Incalzi R, Fuso L, De Rosa M, et al. Co-morbidity contributes to predict mortality of patients with chronic obstructive pulmonary disease. Eur Respir J 1997; 10: 2794-2800.

68. Di Fazio I, Franzoni S, Frisoni GB, et al. Predictive role of single diseases and their combination on recovery of balance and gait in disabled elderly patients. J Am Med Dir Assoc 2006; 7: 208-211.

69. Tinetti ME, Bogardus ST Jr, Agostini JV. Potential pitfalls of disease-specific guidelines for patients with multiple conditions. N Engl J Med 2004; 351: $2870-2874$.

70. Lee JH, Lee DS, Kim EK, et al. Simvastatin inhibits cigarette smoking-induced emphysema and pulmonary hypertension in rat lungs. Am J Respir Crit Care Med 2005; 172: 987-993.

71. Morimoto K, Janssen WJ, Fessler MB, et al. Lovastatin enhances clearance of apoptotic cells (efferocytosis) with implications for chronic obstructive pulmonary disease. J Immunol 2006; 176: 7657-7665.

72. van der Harst P, Voors A, van Gilst W, et al. Statins in the treatment of chronic heart failure: biological and clinical considerations. Cardiovasc Res 2006; [ Epub ahead of print].

73. Mancini GBJ, Etminan M, Zhang B, Levesque LE, FitzGerald M, Brophy JM. Reduction of morbidity and mortality by statins, angiotensin-converting enzyme inhibitors, and angiotensin receptor blockers in patients with chronic obstructive pulmonary disease. J Am Coll Cardiol 2006; 47: 2554-2560.

74. Tan WC, Qiu D, Liam BL, et al. The human bone marrow response to acute air pollution caused by forest fires. Am J Respir Crit Care Med 2000; 161: 1213-1217.

75. Terashima T, Wiggs B, English D, Hogg JC, van Eeden SF. Phagocytosis of small carbon particles (PM10) by alveolar macrophages stimulates the release of polymorphonuclear leukocytes from bone marrow. Am J Respir Crit Care Med 1997; 155: 1441-1447.

76. van Eeden SF, Hogg JC. The response of human bone marrow to chronic cigarette smoking. Eur Respir J 2000; 15: 915-921.

77. van Eeden SF, Hogg JC. Systemic inflammatory response induced by particulate matter air pollution: the importance of bone-marrow stimulation. $J$ Toxicol Environ Health $A$ 2002; 65: 1597-1613.

78. Charo IF, Ransohoff RM. The many roles of chemokines and chemokine receptors in inflammation. N Engl J Med 2006; 354: 610-621.

79. Gan WQ, Man SF, Senthilselvan A, Sin DD. Association between chronic obstructive pulmonary disease and systemic inflammation: a systematic review and a meta-analysis. Thorax 2004; 59: 574-580.

80. Barnes PJ, Shapiro SD, Pauwels RA. Chronic obstructive pulmonary disease: molecular and cellular mechanisms. Eur Respir J 2003; $22: 672-688$.

81. Hogg JC. Pathophysiology of airflow limitation in chronic obstructive pulmonary disease. Lancet 2004; 364: 709-721.

82. Hansson GK. Inflammation, atherosclerosis, and coronary artery disease. N Engl J Med 2005; 352: 1685-1695. 